\title{
A new kind of parameter conjugate gradient for unconstrained optimization
}

\author{
Basim A. Hassan ${ }^{1}$, Hussein O. Dahawi², Azzam S. Younus ${ }^{3}$ \\ ${ }^{1}$ Department of Mathematics, College of Computers Sciences and Mathematics, University of Mosul, Iraq \\ ${ }^{2,3}$ Department of Mathematics, College of Education of Pure Sciences, University of Mosul, Iraq
}

\section{Article Info}

\section{Article history:}

Received Mar 4, 2019

Revised Jun 2, 2019

Accepted Jul 12, 2019

\section{Keywords:}

Conjugate gradient methods

Convergence property

Sufficient descent property

\begin{abstract}
The key feature for conjugate gradient methods is a conjugate parameter optimal for solving unrestrained minimization functions. In this paper, a replacement new parameter conjugate gradient for unconstrained optimization. The sufficient descent property cleave to. The global convergence property of the new method is proved under some assumptions. Numerical results explain that the new parameter is superior in practice.
\end{abstract}

\section{Corresponding Author:}

Basim A. Hassan

Department of Mathematics,

College of Computers Sciences and Mathematics,

University of Mosul, Iraq

Email: basimabas39@gmail.com

\section{INTRODUCTION}

In the literature several optimization strategies may be originate with (theoretically) a much better speed of convergence than the descent gradient methods. Maybe the foremost documented ones area unit the conjugate gradient and quasi-Newton strategies. For details see [1].

Generally, for $n$ number of variables of the problem has the following from:

$$
\min \left\{f(x) \mid x \in R^{n}\right\}
$$

where $f: R^{n} \rightarrow R^{1}$ is a continuously derivable function.

Nonlinear conjugate gradient algorithms are based on the following iterative scheme :

$$
x_{0} \in R^{n}, \quad x_{k+1}=x_{k}+\alpha_{k} d_{k}
$$

where the search direction $d_{k+1}$ is outlined as a linear combination of the present by product $\eta_{k+1}$ and also the earlier search direction $d_{k}$ :

$$
d_{0}=-\eta_{0}, d_{k+1}=-\eta_{k+1}+\beta_{k} d_{k}
$$


where $\beta_{k}$ is a parameter conjugate gradient, $\eta_{k+1}$ denotes gradient of $f\left(x_{k+1}\right)$ at the point $x_{k+1}$, $s_{k}=x_{k+1}-x_{k}$ and $y_{k}=\eta_{k+1}-\eta_{k}$. More details can be found in [2].

The step size $\alpha_{k}$ is decided in line with the Wolfe line search states as follows :

$$
\begin{aligned}
& f\left(x_{k}\right)-f\left(x_{k}+\alpha_{k} d_{k}\right) \geq-\delta \alpha_{k} \eta_{k}^{T} d_{k} \\
& \text { " } \eta\left(x_{k}+\alpha_{k} d_{k}\right)^{T} d_{k} \geq \sigma \eta_{k}^{T} d_{k} "
\end{aligned}
$$

where $0<\delta<\sigma<1$ and $d_{k}$ is a descent direction $\eta_{k}^{T} d_{k}<0$. For details see [3].

It is well known that if the matrix of gradient is positive definite, the most efficient search direction at $x_{k}$ is the Newton direction:

$$
d_{k+1}=-\left(\nabla \eta_{k+1}\right)^{-1} \eta_{k+1}=-G_{k+1}^{-1} \eta_{k+1}
$$

From the secant condition that :

$$
\left(\nabla \eta_{k+1}\right)^{T} s_{k}=y_{k}
$$

More details can be found in [4].

The conjugate gradient methods different depend on the calculation of parameters $\beta_{k}$. The idea of variant CG methods had been studied by many researchers for example, see (Hestenes and Stiefel [5]) and (Fletcher and Reeves [6]).

$$
\beta_{k}^{H S}=\frac{\eta_{k+1}^{T} y_{k}}{y_{k}^{T} d_{k}}, \quad \beta_{k}^{F R}=\frac{\eta_{k+1}^{T} \eta_{k+1}}{\eta_{k}^{T} \eta_{k}}
$$

The motivation of this paper is to combine the advantages of conjugate gradient direction $d_{k+1}^{C G}$ and Newton direction $d_{k+1}^{N}$ in order to provide novel parameter with better convergence.

\section{A NEW KING OF PARAMETER CONJUGATE GRADIENT}

In this section, we derive a new parameter conjugate gradient based on the three order tensor model. Based on the three order tensor model, the information of the second order curvature in the following from:

$$
s_{k}^{T} G_{k+1} s_{k}=y_{k}^{T} s_{k}+6\left(f_{k}-f_{k+1}\right)+3\left(\eta_{k+1}+\eta_{k}\right)^{T} s_{k}
$$

For more details can be found in [7].

The step size $\alpha_{k}$ determine by many algorithms, in exact line search the step length $\alpha_{k}$ is choose as :

$$
\alpha_{k}=-\frac{\eta_{k}^{T} d_{k}}{d_{k}^{T} G d_{k}}
$$

We produce the steps, that lead to a new second order curvature as below :

$$
s_{k}^{T} G_{k+1} s_{k}=\left(f_{k}-f_{k+1}\right)+\frac{2}{3} \eta_{k+1}^{T} s_{k}-\frac{3}{6} \eta_{k}^{T} s_{k}
$$


which implies that :

$$
G_{k+1}=\frac{\left(f_{k}-f_{k+1}\right)+2 / 3 \eta_{k+1}^{T} s_{k}-1 / 2 \eta_{k}^{T} s_{k}}{s_{k}^{T} s_{k}} I_{n \times n}
$$

Since $y_{k}^{T} s_{k}=\eta_{k+1}^{T} s_{k}-\eta_{k}^{T} s_{k}$, then from the above equation, we have:

$$
G_{k+1}=\frac{\left(f_{k}-f_{k+1}\right)+1 / 2 y_{k}^{T} s_{k}+1 / 6 \eta_{k+1}^{T} s_{k}}{s_{k}^{T} s_{k}} I_{n \times n}
$$

Then Newton direction can be written as :

$$
d_{k+1}=-\left(\frac{s_{k}^{T} s_{k}}{\left(f_{k}-f_{k+1}\right)+1 / 2 y_{k}^{T} s_{k}+1 / 6 \eta_{k+1}^{T} s_{k}}\right) \eta_{k+1}
$$

By combine the advantages of $d_{k+1}^{C G}$ and $d_{k+1}^{N}$, so, the equation is hold :

$$
-\left(\nabla \eta_{k+1}\right)^{-1} \eta_{k+1}=-\eta_{k+1}+\beta_{k} d_{k}
$$

Now, we'll realize the parameter $\beta_{k}$.Equation (15) multiplied by $y_{k}^{T}$, then we get :

$$
\begin{aligned}
& -\left(\frac{s_{k}^{T} s_{k}}{\left(f_{k}-f_{k+1}\right)+1 / 2 y_{k}^{T} s_{k}+1 / 6 \eta_{k+1}^{T} s_{k}}\right) \eta_{k+1}^{T} y_{k}=-\eta_{k+1}^{T} y_{k}+\beta_{k} d_{k}^{T} y_{k} \\
& \beta_{k} d_{k}^{T} y_{k}=-\left(\frac{s_{k}^{T} s_{k}}{\left(f_{k}-f_{k+1}\right)+1 / 2 y_{k}^{T} s_{k}+1 / 6 \eta_{k+1}^{T} s_{k k}}\right) \eta_{k+1}^{T} y_{k}+\eta_{k+1}^{T} y_{k}
\end{aligned}
$$

from (16) we get :

$$
\beta_{k} d_{k}^{T} y_{k}=\left(1-\frac{s_{k}^{T} s_{k}}{\left(f_{k}-f_{k+1}\right)+1 / 2 y_{k}^{T} s_{k}+1 / 6 \eta_{k+1}^{T} s_{k}}\right) \eta_{k+1}^{T} y_{k}
$$

then we have :

$$
\beta_{k}=\left(1-\frac{s_{k}^{T} s_{k}}{\left(f_{k}-f_{k+1}\right)+1 / 2 y_{k}^{T} s_{k}+1 / 6 \eta_{k+1}^{T} s_{k}}\right) \frac{\eta_{k+1}^{T} y_{k}}{d_{k}^{T} y_{k}}
$$

Then the new conjugate gradient directions are :

$$
d_{k+1}=-g_{k+1}+\left(1-\frac{s_{k}^{T} s_{k}}{\left(f_{k}-f_{k+1}\right)+1 / 2 y_{k}^{T} s_{k}+1 / 6 \eta_{k+1}^{T} s_{k}}\right) \frac{\eta_{k+1}^{T} y_{k}}{d_{k}^{T} y_{k}} d_{k}
$$

For simplicity,we call equation (17) by $\beta_{k}^{B A H}$ methods. Also $\beta_{k}^{B A H}$ can be write in the manner : 


$$
\beta_{k}^{B A H}=\frac{1}{r_{k}^{T} y_{k}}\left(y_{k}-r \frac{\left\|y_{k}\right\|^{2}}{s_{k}^{T} y_{k}} s_{k}\right)^{T} \eta_{k+1}
$$

Where:

$$
r=\frac{\left(s_{k}^{T} y_{k}\right)^{2}}{\left\|y_{k}\right\|^{2}}\left[\frac{s_{k}^{T} y_{k}}{s_{k}^{T} s_{k}} * \frac{s_{k}^{T} s_{k}}{\left(f_{k}-f_{k+1}\right)+2 / 3 \eta_{k+1}^{T} s_{k}-1 / 2 \eta_{k}^{T} s_{k}}\right]
$$

Now we are ready to state the steps of the new conjugate gradient methods. New Algorithms (BAH Algorithms) :

Step 1. Give $x_{1} \in R^{n}$. Set $k=1$ and $d_{1}=-\eta_{1}$.

Step 2. Stop if $\left\|\eta_{1}\right\| \leq 10^{-6}$. Otherwise, continue.

Step 3. Find $\alpha_{k+1}>0$ fulfilling the Wolfe states (4) and (5).

Step 4. Set $x_{k+1}=x_{k}+\alpha_{k} d_{k}$. If $\left\|\eta_{k+1}\right\| \leq 10^{-6}$, then stop.

Step 5. Compute $\beta_{k}$ by the formulaes (19) and $d_{k+1}$ by (3).

Step 6. Put $k=k+1$. Go to step 2 .

\section{CONVERGENT ANALYSIS} assumption.

Global convergence of the BAH-algorithm will be proved in this section under the following

\section{Assumptions}

i- $f(x)$ is bounded below on $R^{n}$. ii- The gradient $\eta(x)$ is Lipschitz continuous, namely, there exists $L>0$ such that :

$$
\left\|\eta\left(x_{k+1}\right)-\eta\left(x_{k}\right)\right\| \leq L\left\|x_{k+1}-x_{k}\right\|, \forall x_{k+1}, x_{k} \in U
$$

Under these assumptions on $f$, then a constant $\Gamma>0$ exists, such that :

$$
\left\|\eta_{k+1}\right\|>\Gamma
$$

for all $x \in L$. More details can be found in [8].

The sufficient descent condition has a very important property.

\subsection{Sufficient descent condition}

For the sufficient states to hold, then :

$$
d_{k+1}^{T} \eta_{k+1} \leq-c\left\|\eta_{k+1}\right\|^{2}, c>0
$$

\section{Theorem 3.1}

Let $s_{k}, y_{k}, \eta_{k+1} \in R^{n}, \beta_{k} \in R$ and $\beta_{k}$ defined by (19) where $t \in(1 / 4, \infty)$. If $s_{k}^{T} y_{k} \neq 0$, then $d_{k+1}^{T} \eta_{k+1} \leq-\left[1-\frac{1}{4 r}\right]\left\|\eta_{k+1}\right\|^{2}$ 
Proof :

Since $d_{0}=-\eta_{0}$, we have $\eta_{0}^{T} d_{0}=-\left\|\eta_{0}\right\|^{2}$, which satisfy (23). Multiplying (16) by $\eta_{k+1}$, we have :

$$
d_{k+1}^{T} \eta_{k+1}=-\left\|\eta_{k+1}\right\|^{2}+\left(\frac{\eta_{k+1}^{T} y_{k}}{s_{k}^{T} y_{k}}-r \frac{\left\|y_{k}\right\|^{2}}{\left(s_{k}^{T} y_{k}\right)^{2}} \eta_{k+1}^{T} s_{k}\right) s_{k}^{T} \eta_{k+1}
$$

Yielding :

$$
d_{k+1}^{T} \eta_{k+1}=\frac{\left(\eta_{k+1}^{T} y_{k}\right)\left(s_{k}^{T} \eta_{k+1}\right)\left(s_{k}^{T} y_{k}\right)-\left\|\eta_{k+1}\right\|^{2}\left(s_{k}^{T} y_{k}\right)^{2}-r\left\|y_{k}\right\|^{2}\left(\eta_{k+1}^{T} s_{k}\right)^{2}}{\left(s_{k}^{T} y_{k}\right)^{2}}
$$

We applying the inequality $w^{T} v \leq \frac{1}{2}\left(\|w\|^{2}+\|v\|^{2}\right)$ with $w=\frac{1}{m}\left(s_{k}^{T} y_{k}\right) \eta_{k+1}$ and $v=m\left(\eta_{k+1}^{T} s_{k}\right) y_{k} \quad$ where $m \in\left(\frac{1}{\sqrt{2}}, \sqrt{2 r}\right]$, to the first term of the above equality, we get :

$$
\left(\eta_{k+1}^{T} y_{k}\right)\left(s_{k}^{T} \eta_{k+1}\right)\left(s_{k}^{T} y_{k}\right) \leq \frac{1}{2}\left[\frac{1}{m^{2}}\left(s_{k}^{T} y_{k}\right)^{2}\left\|\eta_{k+1}\right\|^{2}+m^{2}\left(s_{k}^{T} \eta_{k+1}\right)^{2}\left\|y_{k}\right\|^{2}\right]
$$

This yields :

$$
d_{k+1}^{T} \eta_{k+1} \leq \frac{\left[\frac{1}{2 m^{2}}-1\right]\left(s_{k}^{T} y_{k}\right)^{2}\left\|\eta_{k+1}\right\|^{2}+\left[\frac{m^{2}}{2}-r\right]\left(s_{k}^{T} \eta_{k+1}\right)^{2}\left\|y_{k}\right\|^{2}}{\left(s_{k}^{T} y_{k}\right)^{2}}
$$

from (23) we get :

$$
d_{k+1}^{T} \eta_{k+1} \leq\left[\frac{1}{2 m^{2}}-1\right]\left\|\eta_{k+1}\right\|^{2} \leq-\left[1-\frac{1}{2 m^{2}}\right]\left\|\eta_{k+1}\right\|^{2}
$$

Therefore, we get :

$$
d_{k+1}^{T} \eta_{k+1} \leq-\left[1-\frac{1}{4 r}\right]\left\|\eta_{k+1}\right\|^{2}
$$

Next we will show that CG methods with BAH converges globally.

\subsection{Global convergence property} Wolfe.

Dai et al. expressed in [9] that the subsequent result had been basically established Zoutendijk and

\section{Lemma 1.}

Let assumptions (i) and (ii) holds. The $\alpha_{k}$ is take by the Wolfe line search (4) and (5). If :

$$
\sum_{k \geq 0} \frac{1}{\left\|d_{k+1}\right\|^{2}}=\infty
$$


then

$$
\lim _{k \rightarrow \infty} \inf \left\|\eta_{k+1}\right\|=0
$$

\section{Theorem 3.2}

Presume that the states in Assumption hold. If $\left\{d_{k+1}\right\}$ and $\left\{\eta_{k+1}\right\}$ are generated by new technique, then $\lim _{n \rightarrow \infty} \inf \left\|\eta_{k+1}\right\|=0$.

\section{Proof :}

From (6) and definition of $\beta_{k}$ by (19) we get :

$$
\begin{aligned}
& \left\|d_{k+1}\right\|=\left\|-\eta_{k+1}+\beta_{k} d_{k}\right\| \leq\left\|\eta_{k+1}\right\|+\left|\beta_{k}\right|\left\|d_{k}\right\| \\
& \left\|d_{k+1}\right\| \leq\left\|\eta_{k+1}\right\|+\left\|\left(y_{k}-r \frac{\left\|y_{k}\right\|^{2}}{s_{k}^{T} y_{k}} s_{k}\right)\right\| \frac{\left\|\eta_{k+1}\right\|}{\left\|s _ { k } \left|\left\|\mid y_{k}\right\|\right.\right.}\left\|s_{k}\right\| \\
& \leq\left\|\eta_{k+1}\right\|+\frac{\left\|y _ { k } \left|\left\|\mid \eta_{k+1}\right\|+r \frac{\left\|\eta _ { k + 1 } \left|\left\|\mid y_{k}\right\|^{2}\left\|s_{k}\right\|\right.\right.}{\left\|s _ { k } \left|\left\|\mid y_{k}\right\|\right.\right.}\right.\right.}{\left\|s_{k} \mid\right\| y_{k} \|}\left\|s_{k}\right\| \\
& \leq\left\|\eta_{k+1}\right\|+\frac{\left\|y_{k}\right\|\left\|\eta_{k+1}\right\|+r\left\|\eta_{k+1}\right\|\left\|y_{k}\right\|}{\left\|s_{k}\right\|\left\|y_{k}\right\|}\left\|s_{k}\right\| \\
& \leq[2+r]\left\|\eta_{k+1}\right\|
\end{aligned}
$$

This relation explain to facilitate :

$$
\sum_{k \geq 1} \frac{1}{\left\|d_{k+1}\right\|^{2}} \geq\left(\frac{1}{2+r}\right) \frac{1}{\Gamma} \sum_{k \geq 1} 1=\infty
$$

Consequently, from Lemma 1 we have $\lim _{k \rightarrow \infty} \inf \left\|\eta_{k+1}\right\|=0$, which for target perform is uniformly, then equivalent to $\lim _{k \rightarrow \infty}\left\|\eta_{k+1}\right\|=0$.

\section{NUMERICAL RESULTS}

We tested BAH-algorithm. The test functions and their primary values are wan from [10]. Furthermore, Optimization problems used in many papers for example, see [11-18]. In addition to these functions, there are various other functions that havebeen used for testing in the folloowing research [19-25 ]. The numerical results are reported in Table 1 : "the first column and the second one represent the problem name and its dimension in [10], respectively. NI, NR and NF in the table denote the number of iterations, function evaluations and the number of restart calls, respectively".

All the algorithm area unit enforced in Fortran 90 ninety. All told cases, double preciseness arithmetic were used. The parameters in Wolfe states area unit set as $\delta_{1}=0.001$ and $\delta_{2}=0.9$. BAHalgorithm is efficient we see from Table 1. 
Table 1. The Numerical Results of the FR and BAH Methods

\begin{tabular}{|c|c|c|c|c|c|c|c|}
\hline \multirow[t]{2}{*}{ P. No. } & \multirow[t]{2}{*}{$\mathrm{n}$} & \multicolumn{3}{|c|}{ FR algorithm } & \multicolumn{3}{|c|}{ BAH algorithm } \\
\hline & & NI & NR & $\mathrm{NF}$ & NI & NR & $\mathrm{NF}$ \\
\hline \multirow[t]{2}{*}{1} & 100 & 47 & 18 & 93 & 42 & 21 & 95 \\
\hline & 1000 & 78 & 45 & 131 & 39 & 18 & 86 \\
\hline \multirow[t]{2}{*}{2} & 100 & 32 & 15 & 52 & 22 & 10 & 41 \\
\hline & 1000 & 22 & 10 & 42 & 23 & 12 & 44 \\
\hline \multirow[t]{2}{*}{3} & 100 & 25 & 11 & 43 & 24 & 9 & 45 \\
\hline & 1000 & 46 & 28 & 741 & 25 & 5 & 54 \\
\hline \multirow[t]{2}{*}{4} & 100 & 32 & 13 & 64 & 35 & 16 & 68 \\
\hline & 1000 & 77 & 46 & 129 & 28 & 11 & 55 \\
\hline \multirow[t]{2}{*}{5} & 100 & 15 & 6 & 25 & 17 & 9 & 29 \\
\hline & 1000 & $\mathrm{~F}$ & $\mathrm{~F}$ & $\mathrm{~F}$ & 26 & 20 & 281 \\
\hline \multirow[t]{2}{*}{6} & 100 & 37 & 8 & 67 & 43 & 18 & 69 \\
\hline & 1000 & 73 & 27 & 115 & 58 & 20 & 91 \\
\hline \multirow[t]{2}{*}{7} & 100 & 89 & 32 & 174 & 72 & 45 & 163 \\
\hline & 1000 & 107 & 40 & 211 & 88 & 52 & 226 \\
\hline \multirow[t]{2}{*}{8} & 100 & 32 & 12 & 65 & 24 & 14 & 54 \\
\hline & 1000 & 53 & 22 & 116 & 36 & 21 & 89 \\
\hline \multirow[t]{2}{*}{9} & 100 & 9 & 4 & 18 & 10 & 6 & 18 \\
\hline & 1000 & 12 & 7 & 82 & 9 & 7 & 55 \\
\hline \multirow[t]{2}{*}{10} & 100 & 74 & 21 & 123 & 93 & 30 & 140 \\
\hline & 1000 & 370 & 88 & 616 & 341 & 77 & 567 \\
\hline \multirow[t]{2}{*}{11} & 100 & 69 & 50 & 1202 & 54 & 37 & 653 \\
\hline & 1000 & 98 & 82 & 1967 & 46 & 33 & 502 \\
\hline \multirow[t]{2}{*}{12} & 100 & 23 & 11 & 45 & 21 & 12 & 40 \\
\hline & 1000 & 27 & 11 & 55 & 17 & 9 & 41 \\
\hline \multirow[t]{2}{*}{13} & 100 & 49 & 22 & 66 & 18 & 12 & 33 \\
\hline & 1000 & 129 & 67 & 166 & 13 & 9 & 26 \\
\hline \multirow[t]{2}{*}{14} & 100 & 122 & 62 & 156 & 14 & 9 & 25 \\
\hline & 1000 & 130 & 66 & 166 & 16 & 10 & 29 \\
\hline \multirow[t]{2}{*}{15} & 100 & 112 & 55 & 147 & 44 & 19 & 65 \\
\hline & 1000 & 110 & 54 & 145 & 61 & 34 & 82 \\
\hline Total & & 1999 & 933 & 7022 & 1333 & 585 & 3485 \\
\hline $\begin{array}{l}\text { Extended M } \\
11 \text {. is the EL } \\
\mathrm{BD} 2,15 \text {. is }\end{array}$ & $\begin{array}{l}\text { CUTl } \\
\text { lized }\end{array}$ & $\begin{array}{l}\text { nverge } \\
\text { t for } \\
\text { iagona } \\
\text { Quadr } \\
\text { he LI } \\
\text { '," }\end{array}$ & $\begin{array}{l}\text { Ex } \\
\text { QP } \\
\text { UTH }\end{array}$ & $\begin{array}{l}\text { senbro } \\
\text { ee Exp } \\
\text { ARW } \\
\text { e DEN }\end{array}$ & $\begin{array}{l}\text { the Ex } \\
6 . \text { is th } \\
\text { UTE), } \\
\text { (CUTE }\end{array}$ & $\begin{array}{l}\text { eale, } \\
\text { ized } \\
\text { Partia } \\
\text { e Ext }\end{array}$ & $\begin{array}{l}\text { Gener } \\
2,7 . \\
\text { Qua } \\
\text { ck-Dis }\end{array}$ \\
\hline
\end{tabular}

Can summarize our numerical results in Table 2 based on the percentage performance for all Tools used in these comparisons.

Table 2. Percentage Performance of the Methods

\begin{tabular}{cccc}
\hline & NI & NR & NF \\
\hline FR & $100 \%$ & $100 \%$ & $100 \%$ \\
BAH & $66.68 \%$ & $62.70 \%$ & $49.62 \%$ \\
\hline
\end{tabular}

It is clear from Table 2 that taking, over all the tools as a $100 \%$ for FR method the BAH method has an improvement, in about $33 \% \mathrm{NI} ; 37 \% \mathrm{NR}$ and $50 \% \mathrm{NF}$, these results indicate that New method is in general is the best.

\section{CONCLUSIONS}

A new kind of parameter in the conjugate gradient methods for large-scale unconstrained optimization problems is proposed. Reveal Numerical that the new method is superior in practice with competitive FR method. We choose the parameter $\beta_{k}$ appropriately, to boost the performance of the conjugate gradient methods.

\section{REFERENCES}

[1] Pluim J.P.W., Likar B., and Gerritsen F.A., "A comparison of acceleration techniques for nonrigid medical image registration”, University Medical Center Utrecht, Image Sciences Institute, 2006, pp. 151-159. 
[2] Saman B.K. and Reza G.," hybridization of the Hestenes-Stiefel and Dai-Yuan conjugate gradient methods based on a least-squares approach", Journal Optimization Methods and Software,2014, pp.1-13.

[3] Wolfe, P.," Convergence conditions for ascent methods". SIAM Rev. 11(2), 1969, pp.226-235.

[4] Rao S. S., “ Engineering Optimization Theory and Practice”, 4th edition, John Wiley \& Sons Inc., New Jersey, Canada,2009.

[5] Hestenes, M. R. and Stiefel, E. L., "Method of conjugate gradients for Solving linear systems" Journal National Standards 49, 1952, pp. 409-436.

[6] Fletcher R. and Reeves C. M., "Funtion minimization by conjagate gradients", Computer Journal 7, 1964, pp. 149-154.

[7] Zhang J.Z., Deng N.Y., and Chen L.H.," New quasi-Newton equation and related methods for unconstrained optimization," Journal of Optimization Theory and Applications, vol. 102,1999, pp. 147-167.

[8] Dai Y. H. and Yuan Y.," A nonlinear conjugate gradient method with a strong global convergence property", SIAM J. optimization, 1999, pp. 177-182.

[9] Dai Y.H., Han, J.Y., Liu, G.H., Sun, D.F., Yin, .X. and Yuan, Y., "Convergence properties of nonlinear conjugate gradient methods". SIAM Journal on Optimization, 10,1999,pp. 348-358.

[10] Andrie N., “ An Unconstrained Optimization Test functions collection “ Advanced Modeling and optimization,10, 2009, pp.147-161.

[11] Basim A. H. "A new formula for conjugate parameter computation based on the quadratic model", Indonesian Journal of Electrical Engineering and Computer Science (IJEECS), 2019; 3: 954-961.

[12] Basim A. H. , Hussein K. K. "A new class of BFGS updating formula based on the new quasi-newton equation", Indonesian Journal of Electrical Engineering and Computer Science (IJEECS), 2019; 3: 945-953.

[13] Basim A. H. , Zeyad M. A. and Hawraz N. J. "A descent extension of the Dai - Yuan conjugate gradient technique", Indonesian Journal of Electrical Engineering and Computer Science (IJEECS), 2019; 2: 661-668.

[14] Li C. Fang L. and Cao X. "Global convergenceof a kind of conjugate gradient method". TELKOMNIKA (Telecommunication, Computing, Electronics and Control). 2013; 11: 544-549,2013.

[15] $\mathrm{Li}$ C., "A modified conjugate gradent method for unconstrained optimization," TELKOMNIKA (Telecommunication, Computing, Electronics and Control)", vol. 11, pp. 6373-6380, 2013.

[16] Dauda1 M. K., Mustafa M., Mohamad A., Nor S.A. “ Hybrid conjugate gradient parameter for solving symmetric systems of nonlinear equations", Indonesian Journal of Electrical Engineering and Computer Science (IJEECS), 2019; 16: 539-543.

[17] Gilbert J.C. and Nocedal J., "Global convergence properties of conjugate gradient methods for optimization," SIAM J. Optim. 2 (1992), pp. 21-42.

[18] Hager W.W. and Zhang H., “A survey of nonlinear conjugate gradient methods,” Pac. J. Optim. 2 (2006), pp. 3558.

[19] Li G., Tang C., and Wei Z., "New conjugacy condition and related new conjugate gradient methods for unconstrained optimization,” J. Comput. Appl. Math. 202 (2007), pp. 523-539.

[20] Babaie S. K., "An eigen value study on the sufficient descent property of a modified Polak-Ribi- Polak conjugate gradient method," Bull. Iranian Math. Soc., vol. 40, pp. 235-242, 2014.

[21] Guangming Z., "A descent algorithm without line search for unconstrained optimization," Applied Mathematics and Computation, vol. 215, pp. 2528-2533, 2009.

[22] Ghani N., Kamaruddin S., Ramli M., Musirin I. And Hashim H. "Enhanced BFGS quasi-Newton backpropagation models on MCCI data". Indonesian Journal of Electrical Engineering and Computer Science. 2017;8:101-106.

[23] Ahmad A. and Zabidin S., "Modification of Nonlinear Conjugate Gradient Method with Weak Wolfe-Powell Line Search," Hindawi Abstract and Applied Analysis, 2017, pp. 1-6.

[24] Li D. H. and Fukushima M., "A derivative-free line search and global convergence of Broyden-like methods for nonlinear equations, ” Optimization Methods and Software, 13 (2000), pp.181-201.

[25] Babaie-K. S. ., "A modified BFGS algorithm based on a hybrid secant equation," Sci. China Math. 54 (2011), pp. 2019-2036. 